\title{
AOR
}

Selected Papers of \#AolR2020:

The 22nd Annual Conference of the

Association of Internet Researchers

Virtual Event / 13-16 Oct 2021

\section{BEWARE ASIAN SERVERS: RACIALIZED PERCEPTIONS OF CHEATING AND SKILL AMONG VIDEO GAME PLAYERS}

\author{
Christine Tomlinson \\ University of California, Irvine \\ Sam Srauy \\ Oakland University
}

Online interaction can be rife with hostility (Liu et al., 2018). Social media in particular has been observed as an arena to spread negative, racist, and racialized interactions and beliefs (Mathew et al., 2019), but video games are another area to consider in terms of online racism. Although competitive play makes up a large portion of toxic interactions (Lee, 2016), targeted hostilities are common. In particular, an emphasis on Whiteness and anti-Black behavior is well documented in gaming spaces (Gray, 2017). The design and content of video games may contribute to these dynamics through the inclusion of common racial stereotypes (Srauy \& Cheney-Lippold, 2019). Less is understood, however, about specific forms of racism in gaming.

This theoretical project considers the patterns of racism aimed at Asian players. It is important to keep in mind, given the timeframe, that Covid-19 illuminated many of the cultural embeddings against Asians and Asian-Americans that predate the pandemic. In the United States, there has been a history of hostility directed toward China and Chinese people in the context of epidemic events (Edara, 2020). This creates unique circumstances where anti-Chinese - and, as an extension, anti-Asian - perceptions and behaviors flared up among the public more generally in much less subtle and sometimes violent ways (Edara, 2020).

These issues do not exist in a vacuum and racism is deeply ingrained in society, persisting subconsciously even underneath outwardly supportive attitudes (DeAngelis, 2009). For AsianAmericans, racism often takes the form of subconscious discrimination (DeAngelis, 2009), which is frequently also linked to cultural assumptions of skill (Groen, 2013) in the form of the model minority myth (Alvarez et al., 2006).

However, discrimination may be more strongly related to immigration status than race for Asian (and Latine) people in the US (Bean et al., 2013), suggesting that xenophobia may play a large role in player reactions. Still, the position of Asians and Asian-Americans in the US exists in the context of a shifting barrier between White/non-White (a movement toward a black/non-black

Suggested Citation (APA): Tomlinson, C., \& Srauy, S. (2021, October). Beware Asian Servers: Racialized Perceptions of Cheating and Skill Among Video Game Players. Paper presented at AolR 2021: The 22nd Annual Conference of the Association of Internet Researchers. Virtual Event: AolR. Retrieved from http://spir.aoir.org. 
divide), which interacts with other race-related issues like the model minority myth and "honorary [W]hiteness" (Bean \& Lee, 2009; Bonilla-Silva, 2004).

Despite the privilege afforded by the honorary White status, Asians also face a discursive attack as being machine-like automations and representation of a competitive "evil empire," whose insidiousness encroaches on White spaces, viz. canonical cyberpunk texts such as Blade Runner (see Nakamura, 2002). In these texts, the fear articulated is the supplanting of Whites by Asians in economic and cultural contexts through dishonest means such as "cheating" (Nakamura, 2002, 2009). Yet, Bonilla-Silva (2006) notes that Whites justify their status as one not of privilege but of superior skill. Thus, in our context, we see the rhetorical strategy of attributing White players' gaming success as one of skill, while successes by Asian players as the result of cheating/automation (e.g., aimbots or gold farming). We note the cyberpunk genre is having a renaissance in titles such as Cyberpunk 2077, lending further weight to our claims.

Biased perceptions like these influence video game players' perceptions and the ways that they highlight various behaviors online. Cheating is viewed as linked to Asian servers and, in particular, Chinese players while cheating connected to other countries is not framed as aggressively. This perception is granted legitimacy by outlets focused on gaming. Even in cases where cheating is linked to players in other countries at high rates, the conversation shifts toward the limited data on China without prompting.

This is a pattern that has been present since before 2020 and has led to players hoping to block China from games to prevent cheating, cautioning one another against playing on Asian servers, and questioning the cultural roots of cheating among Chinese players. Users in these spaces call upon stereotypical cultural attributes and apply them in attempts to explain cultural reasons that Chinese players are prone to cheating.

There is another side to discrimination against players from Asian backgrounds as well. Although the link of China to Asian servers promotes a pan-ethnic approach to discussion in many cases, there are fewer accusations towards players from South Korea and Japan, linking their performance instead to a seemingly innate skill at video games and calling up concepts of the model minority myth. Although Nakamura (2002) notes that the cyberpunk genre Otherizes Japanese bodies in particular, the West's tendency to adopt a Pan-Asian discourse (Duara, 2001) affords an elision of China with the "evil empire" because of a Chinese video game cheater imaginary, while popular press stories of Japanese and South Korean "obsessive" gaming carries discourses of skill that intersects with their honorary Whiteness in the West (see Groen, 2013). Future studies should probe these patterns and trends in online racism more deeply to better understand their sources, spread, and potential cultural consequences. 


\section{References}

Alvarez, A. N., Juang, L., \& Liang, C. T. (2006). Asian Americans and racism: When bad things happen to" model minorities." Cultural Diversity and Ethnic Minority Psychology, 12(3), 477.

Bean, F. D., \& Lee, J. (2009). Plus ça change...? Multiraciality and the dynamics of race relations in the United States. Journal of Social Issues, 65(1), 205-219.

Bean, F. D., Lee, J., \& Bachmeier, J. D. (2013). Immigration \& the Color Line at the Beginning of the 21st Century. Daedalus, 142(3), 123-140.

Bonilla-Silva, E. (2004). From bi-racial to tri-racial: Towards a new system of racial stratification in the USA. Ethnic and Racial Studies, 27(6), 931-950.

DeAngelis, T. (2009). Unmasking racial micro aggressions. Monitor on Psychology, 40(2), 42.

Duara, P. (2001). The discourse of civilization and Pan-Asianism. Journal of World History, 99130.

Edara, I. R. (2020). Anti-Asian Racism in the Shadow of COVID-19 in the USA: Reported Incidents, Psychological Implications, and Coping Resources. Journal of Psychological Research, 2(03).

Gray, K. L. (2017). “They're just too urban”: Black gamers streaming on Twitch.In J. Daniels, K. Gregory\& T. M. Cottom (Eds.), Digital Sociologies, 355-67. Policy Press.

Groen, A. (2013, May14). Why gamers in Asia are the world's best eSport athletes. PC World.https://www.pcworld.com/article/2036844/why-gamers-in-asia-are-the-worldsbest-esport-athletes.html

Lee, M. D. (2016, September). Crowdsourcing, communities and social identities: Using citizen science to combat online toxicity. In Joint International Conference on Serious Games (pp. 231-242). Springer, Cham.

Liu, P., Guberman, J., Hemphill, L., \& Culotta, A. (2018). Forecasting the presence and intensity of hostility on Instagram using linguistic and social features. arXiv preprint arXiv:1804.06759.

Mathew, B., Dutt, R., Goyal, P., \& Mukherjee, A. (2019, June). Spread of hate speech in online social media. In Proceedings of the 10th ACM conference on web science (pp. 173-182).

Nakamura, L. (2002). Cybertypes: Race, ethnicity, and identity on the Internet. Routledge. 
Nakamura, L. (2009). Don't hate the player, hate the game: The racialization of labor in World of Warcraft. Critical Studies in Media Communication, 26(2), 128-144.

Srauy, S., \& Cheney-Lippold, J. (2019). Realism in FIFA? How social realism enabled platformed racism in a video game. First Monday. 